\title{
FONTES DE ADUBOS ORGÂNICOS NA PRODUÇÃO DE MUDAS DE PITAIA
}

\author{
Felipe Pereira Dal'Col' \\ Renan Garcia Malikouski² \\ Maurício Raasch Buss ${ }^{3}$ \\ Marcelo Rodrigo Krause ${ }^{4}$ \\ Rafael Costa de Sant'Ana ${ }^{5}$ \\ Rafael Zucateli da Vitória ${ }^{6}$ \\ Hediberto Nei Matiello ${ }^{7}$
}

Resumo: A pitaia (Hylocereus undatus) é uma frutífera exótica que vem se popularizando perante os produtores brasileiros. Com isso, verificou-se a utilização de duas fontes de esterco animal, como tratamentos compostos de solo de barranco + esterco de curral (2:1), solo de barranco + esterco suíno curtido (2:1) e solo de barranco, onde todos foram enriquecidos com a dose de $2 \mathrm{Kg} \mathrm{m}^{-3}$ de superfosfato simples. O experimento foi realizado no Setor de Viveiricultura do Ifes- Campus Santa Teresa. Utilizou-se o delineamento inteiramente casualizado (DIC), com 5 repetições. Transcorridos 75 dias do plantio as mudas foram avaliadas considerando-se a parte aérea e o sistema radicular. Observou-se efeito significativo nos tratamentos aplicados para a produção de mudas de pitaia. Os tratamentos contendo esterco bovino e suíno se apresentaram superiores com relação ao número de brotos, altura de plantas e matéria seca de brotos, o que os indica proporcionar o melhor desenvolvimento de mudas de pitaia, em virtude dos acréscimos nutricionais e nas características físicas do substrato.

Palavras-chave: Esterco animal, sistema radicular, frutífera exótica, cactácea.

\footnotetext{
1 Instituto Federal do Espírito Santo - IFES, Campus Santa Teresa, Santa Teresa, ES, Brasil. E-mail: felipepdalcol@gmail.com.

2 Instituto Federal do Espírito Santo - IFES, Campus Santa Teresa, Santa Teresa, ES, Brasil. E-mail: renan_malikouski@hotmail.com.

3 Instituto Federal do Espírito Santo - IFES, Campus Santa Teresa, Santa Teresa, ES, Brasil. E-mail: mauricioraaschbuss@hotmail.com.

4 Instituto Federal do Espírito Santo - IFES, Campus Santa Teresa, Santa Teresa, ES, Brasil. E-mail: agro.krause@gmail.com.

5 Instituto Capixaba de Pesquisa, Assistência Técnica e Extensão Rural - INCAPER, Centro Regional de Desenvolvimento Rural -Centro Norte, Laboratório de Fisiologia Vegetal e Pós-Colheita, Linhares, ES, Brasil. Email: santanaagronomia@gmail.com

6 Universidade Federal do Espírito Santo - UFES, Centro Universitário Norte do Espírito Santo - CEUNES, São Mateus, ES, Brasil. E-mail: zucateli_rafael@hotmail.com.

7 Instituto Federal do Espírito Santo - IFES, Campus Santa Teresa, Santa Teresa, ES, Brasil. E-mail: hedibertonm@ifes.edu.br.
} 